\title{
Airway immune mediator levels during asthmalike symptoms in young children and their possible role in response to azithromycin
}

Carlsson, Christian J.; Rasmussen, Morten A.; Pedersen, Susanne B.; Wang, Ni; Stokholm, Jakob; Chawes, Bo L.; Bønnelykke, Klaus; Bisgaard, Hans

\section{Published in:}

Allergy

Link to article, DOI:

10.1111/all.14651

Publication date:

2021

Document Version

Peer reviewed version

Link back to DTU Orbit

Citation (APA):

Carlsson, C. J., Rasmussen, M. A., Pedersen, S. B., Wang, N., Stokholm, J., Chawes, B. L., Bønnelykke, K., \& Bisgaard, H. (2021). Airway immune mediator levels during asthmalike symptoms in young children and their possible role in response to azithromycin. Allergy, 76(6), 1754-1764. https://doi.org/10.1111/all.14651

\section{General rights}

Copyright and moral rights for the publications made accessible in the public portal are retained by the authors and/or other copyright owners and it is a condition of accessing publications that users recognise and abide by the legal requirements associated with these rights.

- Users may download and print one copy of any publication from the public portal for the purpose of private study or research.

- You may not further distribute the material or use it for any profit-making activity or commercial gain

- You may freely distribute the URL identifying the publication in the public portal 
DR. CHRISTIAN JAKOB CARLSSON (Orcid ID : 0000-0003-2363-173X)

DR. BO LUND CHAWES (Orcid ID : 0000-0001-6846-6243)

PROF. HANS BISGAARD (Orcid ID : 0000-0003-4131-7592)

Article type $\quad$ : Original Article: Asthma and Lower Airway Disease

Title:

Airway immune mediator levels during asthma-like symptoms in young children and their possible role in response to azithromycin

Christian J. Carlsson ${ }^{1}$; Morten A. Rasmussen ${ }^{1+2}$; Susanne B. Pedersen ${ }^{3}$; Ni Wang ${ }^{1}$; Jakob

Stokholm $^{1}$; Bo L. Chawes ${ }^{1}$; Klaus Bønnelykke ${ }^{1 *}$; Hans Bisgaard ${ }^{1 *}$.

* These authors contributed equally to the study

\section{Affiliations:}

1) COPSAC, Copenhagen Prospective Studies on Asthma in Childhood, Herlev and Gentofte Hospital, University of Copenhagen, Copenhagen, Denmark.

2) Department of Food Science, University of Copenhagen, Frederiksberg, Denmark

3) Department of Biotechnology and Biomedicine, Technical University of Denmark, Lyngby, Denmark;

\section{Correspondence to:}

Professor Hans Bisgaard, MD, DMSc

E-mail: bisgaard@copsac.com; Telephone: 004526803090

Address: Ledreborg Allé 34, 2820 Gentofte, Denmark

Authors Contributions: The guarantor of the study is HB, from conception and design to conduct of the study and acquisition of data, data analysis, and interpretation of data. SB was responsible for measurement of immune mediators in upper airway epithelial lining fluid extracted from filter This article has been accepted for publication and undergone full peer review but has not been through the copyediting, typesetting, pagination and proofreading process, which may lead to differences between this version and the Version of Record. Please cite this article as doi: $\underline{10.1111 / \text { ALL.14651 }}$

This article is protected by copyright. All rights reserved 
papers. CJC has written the first draft of the manuscript. KB contributed to design of the study. All co-authors have provided important intellectual input and contributed considerably to the analyses and interpretation of the data. All authors guarantee that the accuracy and integrity of any part of the work has been appropriately investigated and resolved and all have approved the final version of the manuscript. The corresponding author had full access to the data and had final responsibility for the decision to submit for publication. The corresponding author attests that all listed authors meet authorship criteria and that no others meeting the criteria have been omitted. No honorarium, grant, or other form of payment was given to any of the authors to produce this manuscript.

Source of Funding: All funding received by COPSAC is listed on www.copsac.com. The Lundbeck Foundation (Grant no R16-A1694); The Ministry of Health (Grant no 903516); Danish Council for Strategic Research (Grant no 0603-00280B) and The Capital Region Research Foundation have provided core support to the COPSAC research center.

Running head: Airway immune mediators and azithromycin treatment Word count main manuscript: 4.244

This article has an online data supplement. 
Article type: Original research article

Tables: 10 ( in online data supplement)

Figures: 11 ( 8 in online data supplement)

\section{Conflict of interest:}

All authors declare no potential, perceived, or real conflict of interest regarding the content of this manuscript. The funding agencies did not have any role in design and conduct of the study; collection, management, and interpretation of the data; or preparation, review, or approval of the manuscript. No pharmaceutical company was involved in the study.

Governance: We are aware of and comply with recognized codes of good research practice, including the Danish Code of Conduct for Research Integrity. We comply with national and international rules on the safety and rights of patients and healthy subjects, including Good Clinical Practice (GCP) as defined in the EU's Directive on Good Clinical Practice, the International Conference on Harmonisation's (ICH) good clinical practice guidelines and the Helsinki Declaration. We follow national and international rules on the processing of personal data, including the Danish Act on Processing of Personal Data and the practice of the Danish Data Inspectorate.

\section{Abbreviations:}

$\operatorname{COPSAC}_{2010}=$ Copenhagen Prospective Studies on Asthma in Childhood 2010

$\mathrm{CRP}=\mathrm{C}$-reactive protein

$\mathrm{FDR}=$ False discovery rate

$\mathrm{IFN}=$ Interferon

$\mathrm{IL}=$ Interleukin

$\mathrm{ILC}=$ Innate lymphoid cell

$\mathrm{IQR}=$ interquartile range

$\mathrm{PC}=$ Principal Component 
PCA $=$ Principal Component Analysis

$\mathrm{RCT}=$ Randomized Controlled Trial

$\mathrm{RSV}=$ Respiratory syncytial virus

$\mathrm{SD}=$ standard deviation

\section{ABSTRACT}

2 Background

3 Asthma-like symptoms in young children are orchestrated by the local airway immune response,

4 but current knowledge largely relies on in vitro airway models. Azithromycin has been shown to

5 reduce the duration of episodes with asthma-like symptoms but efficacy may depend on the

6 individual child's immune response.

\section{Objectives}

8 To investigate in vivo upper airway immune mediator levels during episodes with asthma-like

9 symptoms in young children and their ability to predict the clinical response to azithromycin 10 treatment.

11 Methods

12535 children aged 0-3 years from the Copenhagen Prospective Studies of Asthma in Childhood-

132010 mother-child cohort were examined for immune mediator levels in samples of nasal

14 epithelial lining fluid during episodes with asthma-like symptoms as well as in the asymptomatic

15 state. In a sub-study, children with recurrent asthma-like symptoms were randomized to either a 3-

16 day course of oral azithromycin $(10 \mathrm{mg} / \mathrm{kg})(\mathrm{n}=32)$ or placebo $(\mathrm{n}=38)$. In the current study, we

17 compared the pre-treatment immune mediator levels with the clinical response to treatment with

18 azithromycin in an exploratory posthoc analysis.

\section{Results}


20 The immune mediator concentrations during $v s$ outside episodes were significantly upregulated for

21 IFN-y (ratio 1.73), TNF- $\alpha$ (ratio 2.05), IL-1 $\beta$ (ratio 1.45), IL-10 (ratio 1.97), while CCL22 (ratio

220.65 ) was downregulated. Low levels of TNF- $\alpha$ and IL-10 and high levels of CCL22 predicted

23 better treatment response to azithromycin ( $\mathrm{p}$-values $<0.05)$.

\section{Conclusion}

25 Upper airway immune mediator levels were altered during episodes of asthma-like symptoms, and 26 levels of TNF- $\alpha$, CCL22 and IL-10 may predict the response to azithromycin treatment.

27

\section{Word count abstract: 264}

29

30 Keywords, MeSH: Asthma, cytokines, chemokines, allergy and immunology, pediatrics 


\section{INTRODUCTION}

32 Episodes of asthma-like symptoms are prevalent among preschool children in westernized 33 countries, with one in three children suffering at least one episode in their first three years of 34 life. ${ }^{1,2}$ Despite the high prevalence, there is little evidence regarding the pathophysiology and 35 treatment of such episodes. ${ }^{3}$ We recently demonstrated a significant reduction by $60 \%$ in the 36 duration of episodes with asthma-like symptoms in a randomized controlled trial (RCT) of oral 37 azithromycin compared to placebo, in children aged 1-3 years with recurrent asthma-like 38 symptoms. ${ }^{4}$ Interestingly, the treatment effect was largely independent of the presence of the most 39 common pathogenic airway bacteria or viruses, suggesting that the effect may partly be mediated 40 by immune-modulatory properties of the drug and that the individual child's immune response

41 could determine and predict the clinical response. Point-of-care tools to predict treatment response 42 are needed to limit the use of antibiotics to the children who are likely to benefit from it.

43 The immune response of the airways is mediated by cytokines and chemokines, but current 44 knowledge on topical immune mediator release during episodes of asthma-like symptoms in 45 childhood relies mainly on stimulated in vitro airway models and airway lavage techniques 46 introducing an unknown dilution of airway secretions. ${ }^{5-9}$

47 The aim of this study was to compare undiluted immune mediator levels in vivo in the upper 48 airway epithelial lining fluid during episodes of asthma-like symptoms and in the asymptomatic 49 state. Furthermore, to assess the value of these mediators for predicting treatment response to 50 azithromycin.

\section{METHODS}

\section{The COPSAC 2010 cohort}

55 COPSAC $_{2010}$ is an ongoing, population-based, prospective mother-child cohort with 700 children 56 enrolled at one-week of age during 2009-2010, as previously described in detail. ${ }^{10-12}$ During the 57 first three years of life the children attended the COPSAC research clinic at nine scheduled visits 58 (i.e. at 1 week, 1, 3, 6, 12, 18, 24, 30, and 36 months), as well as for acute care visits during acute 59 asthma-like symptoms. At the acute care visits, the children were examined by study physicians 
60 with pediatric training, who were solely responsible for the diagnosis and treatment strictly

61 adherent to predefined standard operating procedures. ${ }^{4}$

62 Randomized controlled trial of azithromycin for episodes of asthma-like symptoms in children 63 aged $1-3$

64 In a randomized, double-blind, placebo-controlled trial, ${ }^{4}$ we included children from the 65 COPSAC $_{2010}$ cohort, aged 1-3 years who had recurrent episodes of asthma-like symptoms, as 66 described in the online data supplement. Each episode of asthma-like symptoms that occurred 67 through age 1-3 years (or up to a maximum of seven treatments per child) was randomized at 68 each episode to either a 3-day course of azithromycin oral solution, $10 \mathrm{mg} / \mathrm{kg}$ per day or a 69 matching placebo of similar look and taste. Episodes with clinical signs of pneumonia as described 70 in the online data supplement or blood CRP level above $476 \mathrm{nmol} / \mathrm{L}(50 \mathrm{mg} / \mathrm{L})$ were not included 71 in the study. The primary outcome, which was also used in the current study, was diary-verified 72 duration of symptoms after initiation of treatment. The current study is based on a posthoc

73 analysis of the dataset from the original trial.

\section{Measurements of cytokines and chemokines in upper airway epithelial lining fluid}

75 Upper airway epithelial lining fluid from the nasal mucosa was sampled at the planned visits at 2 76 years of age, where the child was without any respiratory symptoms, as well as during episodes of 77 asthma-like symptoms at acute care visits from age 0-3 years i.e. potentially both before and/or 78 after the sample obtained in asymptomatic periods. ${ }^{10}$ Samples from episodes included in the 79 azithromycin vs. placebo trial were obtained before randomization and initiation of treatment. We 80 used a filter-paper sampling technique previously successfully used to evaluate immune mediator

81 profiles in the upper airway epithelial lining fluid of neonates at 1 month of age. ${ }^{13,14}$ Strips of 82 filter-paper (Accuwik Ultra, fibrous hydroxylated polyester sheets, cat no.SPR0730, Pall Life 83 Sciences, Portsmouth, Hampshire, UK) were inserted bilaterally into the anterior part of the 84 inferior turbinate of the nasal cavity. After 2 minutes of absorption the filter-papers were removed 85 and immediately frozen at $-80^{\circ} \mathrm{C}$. Sex, age and season at sampling was recorded as seasonal 86 fluctuations in upper airway immune mediator levels has previously been documented. ${ }^{15}$ 87 Epithelial lining fluid samples were analyzed using MesoScale Discovery multiplexed array 88 system (MesoScale Discovery, Gaithersburg, Md) as described in the online data supplement. 
89 During the process of laboratory analyses we recorded date of extraction from filter-papers, date 90 and batch of analysis.

91 The epithelial lining fluid samples were analyzed for the following protein immune mediators:

92 IL(interleukin)-12p70, CXCL10 (IP-10), Interferon-gamma (IFN- $\gamma$ ), Tumor necrosis factor-alpha

93 (TNF- $\alpha$ ), CCL4 (MIP-1 $\beta$ ), CCL2 (MCP-1), CCL13 (MCP-4), IL-4, IL-5, IL-13, CCL11 (eotaxin-

94 1), CCL26 (eotaxin-3), CCL17 (TARC), CCL22 (MDC), IL-1ß, CXCL8 (IL-8), IL-10, and IL-2.

95 Selection of the immune mediators was decided a priori to represent different types of immune

96 responses: Type 1 (Th1/CD8+/NK cells/innate lymphoid cells (ILC) 1), Type 2 (Th2, eosinophils,

97 ILC2), Type 17 (neutrophils, ILC3), and regulatory type responses. Moreover, both acute and

98 planned samples from children participating in the azithromycin vs. placebo trial were analyzed

99 for levels of C-reactive protein (CRP), an acute phase reactant and activator of the complement

100 system, in the epithelial lining fluid as described in the online data supplement.

101 At the time of immune mediator sampling we also collected hypopharyngeal aspirates for routine

102 bacterial cultures of $H$ influenzae, S pneumoniae and M catarrhalis and nasopharyngeal aspirates

103 for PCR identification of a range of viral pathogens as detailed in the online data supplement.

105 Daily prospective monitoring of asthma-like symptoms

106 Diary cards were used from birth to monitor burden of asthma-like symptoms between visits as

107 previously validated. ${ }^{16}$ Asthma-like symptoms were explained to the parents as any symptom

108 significantly affecting the child's breathing, such as noisy breathing (wheeze or whistling sounds),

109 shortness of breath, or persistent troublesome cough affecting the child's sleep or activity.

110 Symptoms were recorded daily as individual components of wheeze, dyspnea and cough with any

111 one component signifying a day with asthma-like symptoms. An episode of asthma-like symptoms

112 was defined as at least 3 consecutive days during which the child had symptoms. Samples from

113 episodes with clinical signs indicative of pneumonia or croup were excluded from this study, as

114 described in the online data supplement.

\section{Statistics}

116 Raw levels of all immune mediators $(\mathrm{pg} / \mathrm{mL})$ obtained during asymptomatic periods and during

117 asthma-like symptoms were summarized using median and interquartile ranges (IQR). Before

118 further analyses, immune mediator concentrations were z-scored to make mediators with different 
119 ranges of concentration directly comparable. Concentrations were also total-sum normalized per

120 sample (immune mediator concentration/sum of all immune mediator concentrations in sample) to

121 account for a high with-in sample collinearity of immune mediator levels, likely due to varying

122 amounts of nasal secretion collected on the filter papers, as described in the online data

123 supplement. ${ }^{17}$ The correlation between the various immune mediator levels were calculated and

124 plotted in hierarchical clustering heatmaps. Differences in immune mediator levels during

125 episodes of asthma-like symptoms compared to asymptomatic periods were analyzed using linear

126 mixed effect models with mediator levels as response variables and clinical state (i.e. during or

127 outside episodes) as the explanatory variable. Sampling covariates (i.e. sex, age and season), date

128 of extraction from filter-papers, date of analysis, and batch of analysis were included in the model,

129 as described in the online data supplement. The individual participant identifier was also included

130 in the model as a random effect to adjust for repeated measurements in the samples obtained

131 during episodes of asthma-like symptoms. Results are reported as ratios of the mediator

132 concentration during episodes of asthma-like symptoms compared to asymptomatic periods with

$13395 \%$ confidence intervals (CI) and both nominal and false discovery rate (FDR) adjusted p-values.

134 To circumvent a potential multiple testing issue we applied a principal component analysis (PCA)

135 which decomposes the signal from the 18 mediators into three independent principal components

136 (PCs) that capture the overall variation in the mediator levels and compared the PC scores during

137 episodes of asthma-like symptoms vs. asymptomatic periods. PCs were also included as the

138 explanatory variable in linear mixed effect models.

139 The overall treatment effect of azithromycin on episode duration was analyzed using a Poisson

140 regression model with a log link in accordance with methods used in the original study. ${ }^{4}$ The

141 effect of immune mediator levels on the treatment response to azithromycin was analyzed using

142 linear mixed effect models with duration of episodes as outcome variable and treatment arm (i.e.

143 azithromycin or placebo) as the explanatory variable with mediator levels as an interaction term.

144 Analyses were adjusted for findings of viral and/or bacterial airway infections as described in the

145 online data supplement. Results are reported as factor change in treatment effect per increase of 1

146 standard deviation (SD) of immune mediator concentration in samples obtained during episodes of

147 asthma-like symptoms.

148 Plots showing symptom duration after initiation of treatment in relation to immune mediator levels

149 (SDs of concentration) for both treatment arms are shown as well as graphs showing the derived 
150 treatment effect (i.e. the difference between the two treatment arms at any concentration) in 151 relation to immune mediator levels.

152 We finally performed unadjusted sub-analyses using raw (non-z-scored, non-normalized) immune

153 mediator levels in order to test the predictive performance in a situation closer to a clinical setting,

154 where only data from a single individual would be available. We tested the association with

155 treatment response for a subset of single mediator levels as well as ratios between up- and down-

156 regulated immune mediators, as a simple alternative to normalization. All data analyses were 157 conducted using the statistical software R v3.4.0 (R Core Team, 2015) and the add-on package $158 \quad$ lme4.

159

160

\section{RESULTS}

162 Of the 700 children included in the COPSAC 2010 cohort, $535(76 \%)$ had available samples for 163 immune mediator analyses obtained during episodes of asthma-like symptoms and/or during 164 asymptomatic periods (Table E1). The sample study base (Figure 1) included 522 samples from 165292 children obtained during episodes of asthma-like symptoms and 441 samples from 441

166 children obtained in asymptomatic periods as detailed in the online data supplement. Ninety-four 167 children provided only one or more samples obtained during asthma-like symptoms, 243 provided 168 only a sample obtained during asymptomatic periods and 198 children provided both types of 169 samples.

170 Thirty-two samples obtained during episodes were excluded due to a diagnosis of pneumonia 171 while seven samples obtained in asymptomatic periods were excluded due to adjacent diary 172 recordings of asthma-like symptoms. Hence, 490 samples from 282 children (mean age 1.3 years $173+/-0.6 \mathrm{SD}$ ) obtained during episodes of asthma-like symptoms and 434 samples from 434 children 174 (mean age 2.1 years +/- 0.2 SD) obtained in asymptomatic periods were included in the analyses. 175 Sampling time points for included samples obtained during and outside of symptoms are shown in 176 Figure E1. The median number of samples obtained during symptomatic episodes was 1 [IQR 1177 2]; (min. 1, max. 9). Distribution of sex, age, and season between the two sample groups are 178 shown in Table E2. Raw levels of immune mediators obtained during asthma-like symptoms and 179 in asymptomatic periods are shown in Table 1. 
180 The sample study base for measurement of CRP levels were 68 samples from 42 children obtained

181 during episodes of asthma-like symptoms and 27 samples from 27 children obtained outside of

182 episodes as described in the online data supplement and shown in Figure E2.

\section{3}

184 Upper airway immune mediator levels during episodes of asthma-like symptoms compared to

185 asymptomatic periods

186 Several immune mediators were significantly up- or downregulated during episodes of asthma-like

187 symptoms compared to asymptomatic periods (Figure 2 and Table 2). IFN-y (ratio episode of

188 asthma-like symptoms/asymptomatic period, 1.73, 95\% CI [1.33;2.26], p < 0.01, FDR adjusted

$189 \mathrm{p}=0.06)$, TNF- $\alpha(2.05,[1.55 ; 2.72], \mathrm{p}<0.01$, FDR adjusted $\mathrm{p}=0.02)$, IL-1 $\beta(1.45,[1.13 ; 1.87], \mathrm{p}=$

190 0.01, FDR adjusted $\mathrm{p}=0.06)$, IL-10 (1.97, [1.39;2.79], $\mathrm{p}=0.02$, FDR adjusted $\mathrm{p}=0.11)$ were

191 upregulated, while CCL22 $(0.65,[0.43 ; 0.99], p=0.05$, FDR adjusted $p=0.18)$ was downregulated.

192 Level of CRP in upper airway epithelial lining fluid samples, where such assessment was

193 available, was also upregulated during episodes $(1.74,[1.23 ; 2.45], \mathrm{p}<0.01)$ as shown in Figure

194 E3. Sensitivity analyses comparing only paired samples from children who contributed both

195 samples obtained during symptoms and in asymptomatic periods (Table E3) or including only

196 samples obtained during symptomatic episodes occurring after the age of two years, i.e. after the

197 asymptomatic sampling, showed similar results. Adjustment for allocated interventions in

198 randomized trials with antenatal dietary fish oil and high-dose vitamin D supplementations carried

199 out the cohort did not change the results (data not shown). Hierarchical clustering heatmaps

200 showed positive correlation and clustering of several immune mediators attributed to the same

201 immune response classes during episodes of asthma-like symptoms, as shown in Figure E4 and

202 detailed in the online data supplement.

203

204 Viral and bacterial findings during episodes of asthma-like symptoms are shown in Table E4.

205 Stratifying analyses for episodes with purely viral $(\mathrm{N}=61)$, purely bacterial $(\mathrm{N}=100)$ or co-

206 infection ( $\mathrm{N}=275)$ generally showed similar immune mediator patterns (Figure E5). I

207 Stratifying analyses by a history of recurrent asthma-like symptoms (N=204 samples obtained

208 during episodes and $\mathrm{N}=130$ in asymptomatic periods) and no such diagnosis ( $\mathrm{N}=286$ samples

209 obtained during episodes and $\mathrm{N}=304$ during asymptomatic periods) did not significantly change

210 the results (Figure E6 and Table E6). 
211 We studied the first three PCs from the PCA model, where PC1 explained 25\%, PC2 16\% and

212 PC3 10\% of the variation in the immune mediator levels. A statistically significant response

213 during episodes of asthma-like symptoms compared to asymptomatic periods were seen for PC1 (2140.39 [-0.72:-0.06], p=0.02) and PC3 (0.59 [0.28:0.89], $\mathrm{p}<0.01)$, while it was borderline significant 215 for PC2 (-0.37 [-0.70:-0.04], $\mathrm{p}=0.07)$. Score plots showing separation in several dimensions of 216 samples obtained during episodes (blue ellipses) compared to asymptomatic periods (red ellipses)

217 are presented in Figure E7. As seen from the corresponding loading plots (Figure E7, panels B and 218 D), IFN-y, TNF- $\alpha$, IL-1 $\beta$, IL-10 and CCL22 all contributed to this separation (vector arrows), with 219 the latter contributing in the opposite direction of the other immune mediators, which aligns with 220 the results from the traditional statistical approach. The correlation between specific immune 221 mediator levels and PCs are shown in Figure E3.

222 Upper airway immune mediator profiles for prediction of treatment response to azithromycin for 223 episodes of asthma-like symptoms

224 Of the 148 episodes of asthma-like symptoms randomized to azithromycin or placebo, filter-paper 225 samples were available from 70 episodes (azithromycin $n=32$; placebo $n=38$ ) in 42 children.

226 Numbers of missing episodes were similar in the two treatment arms (i.e. $\mathrm{N}=42$ in the 227 azithromycin, and $\mathrm{N}=36$ in the placebo group). In this subset of samples, we found an average 228 duration of symptoms after treatment of 3.2 days in the azithromycin group and 8.1 days in the 229 placebo group corresponding to a reduction in duration of episodes of $65.7 \%$ (95\% CI, $23054.3 \% ; 74.4 \%, \mathrm{p}<0.01)$ due to azithromycin treatment.

231 Of the five immune mediators significantly (nominal p-values) up- or downregulated during 232 episodes of asthma-like symptoms, three mediators were associated with the effect of 233 azithromycin on the duration of symptoms (Figure 3 and Table 3). Lower levels of TNF- $\alpha$ and IL23410 before treatment predicted longer duration of episodes in the placebo group (Figure 3, top 235 panel, slope $=-0.79, p=0.03$ and slope $=-0,75 \mathrm{p}=0.03$ respectively) while there were no significant 236 association between immune mediator levels and symptom duration in the azithromycin group. 237 Lower levels of TNF- $\alpha$ and IL-10 predicted a more pronounced treatment effect, i.e. reduction in 238 symptom days and treatment effect decreased for higher mediator levels with a factor 0.50 (TNF$239 \alpha$ ) and 0.50 (IL-10) per increase in SD of concentration (Figure 3, bottom panel). No treatment 240 effect was found above 0.95 SDs (TNF- $\alpha$ ) and 0.90 SDs (IL-10) of concentration. Inversely, 
241 higher levels of CCL22 predicted longer duration of episodes in the placebo group (Figure 3, top 242 panel, slope $=1.07, \mathrm{p}<0.01$ ) while there was no significant association between immune mediator

243 level and symptom duration in the azithromycin group. Higher levels of CCL22 predicted a better 244 treatment effect with a factor 2.36 increase per increase in SD of concentration (Figure 3, bottom 245 panel). No treatment effect was found below -0.71 SDs of concentration for CCL22. Importantly, 246 the three mediators modified the treatment effect so that better response was seen for children with 247 mediator levels opposite to the change typically observed during episodes of asthma-like

248 symptoms (Figure 2), i.e. at low levels of TNF- $\alpha$ and IL-10 and high levels of CCL22. There was 249 no apparent effect of IFN- $\gamma$ or IL-1 $\beta$ levels on the treatment effect of azithromycin. In the original $250 \mathrm{RCT}$, presence of $\mathrm{H}$. Influenzae during the symptomatic episode was associated with a stronger 251 treatment response, but sensitivity analyses stratified for presence of analysis of $\mathrm{H}$. Influenzae $(\mathrm{H}$. 252 Influenzae positive $\mathrm{n}=18$ and negative $\mathrm{n}=49$ ), and adjusted for presence of $\mathrm{H}$. Influenzae showed 253 that this did not affect the results of this study (data not shown).

254 Lower levels of CRP before treatment predicted longer duration of episodes (Figure E8, top panel, $255 \mathrm{p}=0.05)$. There was no significant modification of the treatment effect from levels of CRP 256 although there was a tendency in the same direction as for TNF- $\alpha$ and IL-10 with a factor 0.75 $257[0.52: 1.07]$ decrease in treatment effect per increase in SD of concentration $(p=0.12)$.

258 Unadjusted sub-analyses using raw (non-z-scored, non-normalized) immune mediator levels 259 showed that raw levels of TNF- $\alpha$ and IL-10 were also associated with the effect of azithromycin 260 on the duration of symptoms (factor 0.78 and 0.74 per doubling in concentration $[\mathrm{pg} / \mathrm{mL}]$

261 respectively), although the latter was only borderline significant $(\mathrm{p}=0.05)$ (Table E7). Using a 262 ratio of the raw levels of TNF- $\alpha$ /CCL22 or IL-10/CCL22 resulted in even stronger associations 263 with the effect of azithromycin on the duration of symptoms (factor 0.68 and 0.66 per doubling in 264 ratio respectively) (Table E7).

\section{DISCUSSION}

267 IFN-y, TNF- $\alpha$, IL-1 $\beta$ and IL-10 as well as the acute phase reactant CRP were upregulated in the 268 upper airway mucosa whereas CCL22 was relatively downregulated during episodes of asthma269 like symptoms compared to asymptomatic periods. 
270 TNF- $\alpha$, IL-10 and CCL22 predicted treatment effect of azithromycin for episodes of asthma-like 271 symptoms, with improved responses in episodes where the child was unable to mount a sufficient

272 response of TNF- $\alpha$ and IL-10 while having a relatively increased expression of CCL22 (i.e.

273 mediator levels opposite to what was typically observed during episodes of asthma-like

274 symptoms).

275 Strengths and Limitations

276 A major strength of the current study is the nasal epithelial lining fluid sampling method,

277 providing undiluted in vivo levels of immune mediators from the upper airways. Importantly, the

278 current sampling technique was performed without a stimulation of the immune system, thereby

279 enabling us to quantify the physiological concentrations of immune mediators both during

280 symptomatic episodes and in asymptomatic periods. Even though we do not have samples from

281 lung epithelium, the epithelial lining fluid in upper airways has been suggested to reflect that of

282 the lower airways. ${ }^{18,19}$

283 The close clinical single-center surveillance of the COPSAC $_{2010}$ birth cohort is another strength of 284 this study. COPSAC served de facto as the primary health-care center for the children in the

285 cohort, ensuring a standardized approach to sampling following predefined standard operating

286 procedures, and to diagnosis and treatment according to predefined and validated algorithms. This

287 approach reduced the risk of misclassification of illness and variation in sampling quality.

288 Not all children provided both samples obtained during episodes of asthma-like symptoms and in 289 asymptomatic periods and the majority of samples obtained during symptoms were taken before

290 the scheduled sample at age two years. However, sensitivity analyses including only paired

291 observations and only samples obtained during episodes of asthma-like symptoms occurring after

292 the age of two years respectively confirmed the results of the primary analyses.

293 The analyses of treatment response to azithromycin for episodes of asthma-like symptoms in 294 relation to immune mediator levels were based on an RCT with clearly defined and previously

295 validated endpoints. ${ }^{4}$ However, it is a limitation to this part of the study that we only had samples 296 from 70 of 148 episodes included in the RCT. Immune mediator sampling was often omitted due

297 to the extensive program of investigations performed in relation to the acute visits at the research 298 clinic. However, numbers of missing episodes were similar in the two treatment arms, and the 
299 incomplete sampling of episodes included in the RCT did not bias the results of this study. The 300 average duration of episodes in the two treatment arms, and the overall effect of azithromycin on 301 episode length were comparable to the findings of the main study. ${ }^{4}$ An important limitation is that 302 only children with a history of recurrent asthma-like symptoms were included in the RCT, and the 303 findings cannot be generalized beyond this phenotype.

304 We analyzed 18 cytokines and chemokines, which were chosen a priori to represent various major

305 pathways of the immune system. To circumvent a multiple testing problem, we also applied a

306 dimension reducing multivariate approach using a PCA model, which in an unsupervised fashion

307 decomposes the immune signal from the 18 mediators into a few independent components,

308 capturing the overall variation in the immune mediators. The PCA model confirmed that samples

309 obtained during episodes of asthma-like symptoms were distinctly different from those collected

310 in asymptomatic periods, and further replicated the findings from the conventional statistics

311 showing that IFN-g, TNF- $\alpha$, IL-1b, IL-10 and CCL22 contributed to this distinction. Concordance

312 between results obtained from the conventional statistics and the multivariate approach further

313 enhances confidence in the findings, even though the result for only one immune mediator (TNF-

$314 \alpha$ ) was significant while the results of further two (IFN- $\gamma$ and IL-1 $\beta$ ) were borderline significant

315 after FDR adjustment of p-values.

316 CRP has earlier been reported to be expressed in respiratory epithelium in quantities sufficient for

317 antimicrobial effect and levels are regulated by several upstream immune mediators including

318 TNF- $\alpha$, IL-1b and IL-10. ${ }^{20-22}$ Therefore, the fact that CRP was upregulated along with the

319 immune mediators TNF- $\alpha$ and IL- $1 b$ strengthens our belief in the findings.

\section{Interpretation}

321 This study showed a distinct upper airway immune mediator profile during episodes of asthma-

322 like symptoms in young children when compared to asymptomatic periods. This is to our

323 knowledge the first study to investigate unstimulated in vivo airway immune mediator levels in the

324 epithelial lining fluid during acute asthma-like symptoms in children.

325 The identified upregulated mediators are mainly part of an activated Type 1 and inflammasome-

326 based Type 17 response, while the reduced CCL22 Type 2 response results in less recruitment of

327 Treg and Th2 cells and less eosinophilic infiltration of the airway mucosa. This observation is in 
328 line with the hypothesis that the neutrophil, rather than the eosinophil, is the key effector cell in 329 early childhood lung symptoms. ${ }^{23-26}$ Hierarchical clustering of correlations between various

330 immune mediators showed some grouping of immune mediators according to attributed immune

331 response class, supporting this classification in vivo. The immune profile was independent of a

332 prior diagnosis of recurrent asthma-like symptoms, i.e. long term symptom load, and thus appears

333 to represent an acute response independent of the underlying propensity for asthma-like

334 symptoms.

335 Of particular relevance to clinicians, we found that the levels of TNF- $\alpha$, IL-10 and CCL22 in the 336 upper airway mucosa during acute symptoms may predict response to treatment with

337 azithromycin. Interestingly, the treatment response was most marked in episodes with mediator

338 levels opposite to what was observed in the analysis comparing episodes of asthma-like symptoms

339 with asymptomatic periods (Figure 2). This suggests that the changes in upper airway immune

340 mediator levels observed during acute symptoms may in fact represent a "normal" and beneficial

341 immune response, the absence of which warrants therapeutic intervention with azithromycin.

342 However, this study does not provide any evidence as to the mechanism underlying this

343 observation.

344 The finding that prediction of treatment effect was independent of concurrent viral or bacterial

345 airway infections is in line with the original RCT which showed that the treatment effect of

346 azithromycin was largely independent of such infections.

347 Our finding that specific immune mediators may predict treatment response to azithromycin

348 proposes a possible use of these mediators as predictive biomarkers for targeted therapy. This is

349 important since no other predictive biomarkers are known. As the measurements of immune

350 mediator levels are amenable to point-of-care testing ${ }^{30}$ such applications could be used to guide

351 clinical decision making and restrict use of antibiotics to the children who will benefit the most.

352 However, several steps are needed before potential use in clinical practice. First, the results

353 presented in this study are exploratory post-hoc analyses based on a small subset of episodes and

354 should be viewed as hypothesis generating. Second, a robust method for use in individual patients

355 without need for population-based z-scoring of data must be developed. In this respect it is

356 promising that the findings were confirmed using raw immune mediator levels and ratios of raw

357 levels, the latter representing a practical approach to adjust for varying amounts of secretion. 
359 This study shows a distinct upper airway immune mediator profile during episodes of asthma-like 360 symptoms in early childhood, consistent with neutrophilic inflammation as the dominating acute 361 disease process. Levels of TNF- $\alpha$, IL-10 and CCL22 may predict response to oral azithromycin for 362 such episodes, but this needs replication in larger studies.

\section{ACKNOWLEDGEMENTS}

365 We express our deepest gratitude to the children and families of the COPSAC 2010 cohort study for 366 all their support and commitment. We acknowledge and appreciate the unique efforts of the 367 COPSAC research team, and of technicians Vibeke Holt and Lisbeth Buus Rosholm, Department 368 of Biotechnology and Biomedicine, Technical University of Denmark for expert assistance in 369 extraction and measurements of immune mediators in upper airway lining fluid collected onto 370 filter papers.

371 Dr. Carlsson has nothing to disclose. Mr. Rasmussen has nothing to disclose. Ms. Pedersen has 372 nothing to disclose. Ms. Wang has nothing to disclose. Dr. Stokholm has nothing to disclose. Dr. 373 Chawes has nothing to disclose. Professor Bønnelykke has nothing to disclose. Professor Bisgaard 374 has nothing to disclose. 


\section{REFERENCES}

378 1. Bisgaard H, Szefler S. Prevalence of asthma-like symptoms in young children. Pediatr Pulmonol. 2007 Aug;42(8):723-8.

380 2. Martinez FD, Wright AL, Taussig LM, Holberg CJ, Halonen M, Morgan WJ. Asthma and 381 wheezing in the first six years of life. The Group Health Medical Associates. N Engl J Med. $382 \quad 1995$ Jan 19;332(3):133-8.

383 3. Brand PLP, Baraldi E, Bisgaard H, Boner AL, Castro-Rodriguez JA, Custovic A, et al. Definition, assessment and treatment of wheezing disorders in preschool children: an evidence-based approach. Eur Respir J. 2008 Oct;32(4):1096-110.

386 4. Stokholm J, Chawes BL, Vissing NH, Bjarnadóttir E, Pedersen TM, Vinding RK, et al. Azithromycin for episodes with asthma-like symptoms in young children aged 1-3 years: a randomised, double-blind, placebo-controlled trial. Lancet Respir Med. 2016 Jan;4(1):19-26.

389 5. Kicic A, Sutanto EN, Stevens PT, Knight DA, Stick SM. Intrinsic biochemical and functional differences in bronchial epithelial cells of children with asthma. Am J Respir Crit Care Med. 2006 Nov 15;174(10):1110-8.

392 6. Siegle JS, Hansbro N, Dong C, Angkasekwinai P, Foster PS, Kumar RK. Blocking induction 393 of $\mathrm{T}$ helper type 2 responses prevents development of disease in a model of childhood 394 asthma. Clin Exp Immunol. 2011 Jul;165(1):19-28.

395 7. Sheeran P, Jafri H, Carubelli C, Saavedra J, Johnson C, Krisher K, et al. Elevated cytokine concentrations in the nasopharyngeal and tracheal secretions of children with respiratory syncytial virus disease. Pediatr Infect Dis J. 1999 Feb;18(2):115-22.

398 8. van Schaik SM, Tristram DA, Nagpal IS, Hintz KM, Welliver RC, Welliver RC. Increased production of IFN-gamma and cysteinyl leukotrienes in virus-induced wheezing. J Allergy Clin Immunol. 1999 Apr;103(4):630-6. 
401 9. de Blic J, Midulla F, Barbato A, Clement A, Dab I, Eber E, et al. Bronchoalveolar lavage in children. ERS Task Force on bronchoalveolar lavage in children. European Respiratory Society. Eur Respir J. 2000 Jan;15(1):217-31.

404 10. Bisgaard H, Vissing NH, Carson CG, Bischoff AL, Følsgaard NV, Kreiner-Møller E, et al. 405 Deep phenotyping of the unselected COPSAC2010 birth cohort study. Clin Exp Allergy J Br Soc Allergy Clin Immunol. 2013 Dec;43(12):1384-94.

407 11. Bisgaard H, Bønnelykke K. Fish Oil in Pregnancy and Asthma in Offspring. N Engl J Med. $408 \quad 201723 ; 376(12): 1191-2$.

409 12. Chawes BL, Bønnelykke K, Stokholm J, Vissing NH, Bjarnadóttir E, Schoos A-MM, et al. 410 Effect of Vitamin D3 Supplementation During Pregnancy on Risk of Persistent Wheeze in the Offspring: A Randomized Clinical Trial. JAMA. 2016 Jan 26;315(4):353-61.

412 13. Følsgaard NV, Chawes BL, Rasmussen MA, Bischoff AL, Carson CG, Stokholm J, et al.

413 Neonatal Cytokine Profile in the Airway Mucosal Lining Fluid Is Skewed by Maternal Atopy. Am J Respir Crit Care Med. 2012 Feb 1;185(3):275-80.

415 14. Wolsk HM, L Chawes B, Følsgaard NV, Rasmussen MA, Brix S, Bisgaard H. Siblings Promote a Type 1/Type 17-oriented immune response in the airways of asymptomatic neonates. Allergy. 2016 Jan 25;

418 15. Thysen AH, Rasmussen MA, Kreiner-Møller E, Larsen JM, Følsgaard NV, Bønnelykke K, et al. Season of birth shapes neonatal immune function. J Allergy Clin Immunol. 2015 Oct 27;

420 16. Bisgaard H, Pipper CB, Bønnelykke K. Endotyping early childhood asthma by quantitative symptom assessment. J Allergy Clin Immunol. 2011 May;127(5):1155-1164.e2.

422 17. Thorsen J, Rasmussen MA, Waage J, Mortensen M, Brejnrod A, Bønnelykke K, et al. Infant 423 airway microbiota and topical immune perturbations in the origins of childhood asthma. Nat $424 \quad$ Commun. 2019 01;10(1):5001.

425 18. Joshi P, Kakakios A, Jayasekera J, Isaacs D. A comparison of IL-2 levels in nasopharyngeal and endotracheal aspirates of babies with respiratory syncytial viral bronchiolitis. J Allergy Clin Immunol. 1998 Oct;102(4 Pt 1):618-20. 
428 19. Everard ML, Swarbrick A, Wrightham M, McIntyre J, Dunkley C, James PD, et al. Analysis of cells obtained by bronchial lavage of infants with respiratory syncytial virus infection. Arch Dis Child. 1994 Nov;71(5):428-32.

431 20. Gould JM, Weiser JN. Expression of C-reactive protein in the human respiratory tract. Infect Immun. 2001 Mar;69(3):1747-54.

433 21. Baumann H, Gauldie J. Regulation of hepatic acute phase plasma protein genes by

434 hepatocyte stimulating factors and other mediators of inflammation. Mol Biol Med. 1990 $435 \quad$ Apr;7(2):147-59.

436 22. Girndt M, Ulrich C, Kaul H, Sester U, Sester M, Köhler H. Uremia-associated immune defect: the IL-10-CRP axis. Kidney Int Suppl. 2003 May;(84):S76-79.

438 23. Oommen A, Patel R, Browning M, Grigg J. Systemic neutrophil activation in acute preschool 439 viral wheeze. Arch Dis Child. 2003 Jun;88(6):529-31.

440 24. Marguet C, Jouen-Boedes F, Dean TP, Warner JO. Bronchoalveolar cell profiles in children with asthma, infantile wheeze, chronic cough, or cystic fibrosis. Am J Respir Crit Care Med. 1999 May;159(5 Pt 1):1533-40.

443 25. Bush A. How early do airway inflammation and remodeling occur? Allergol Int Off J Jpn Soc Allergol. 2008 Mar;57(1):11-9.

445 26. Pitrez PMC, Brennan S, Sly PD. Inflammatory profile in nasal secretions of infants

446 hospitalized with acute lower airway tract infections. Respirol Carlton Vic. 2005 $447 \quad$ Jun;10(3):365-70.

448 27. Turato G, Barbato A, Baraldo S, Zanin ME, Bazzan E, Lokar-Oliani K, et al. Nonatopic 449 children with multitrigger wheezing have airway pathology comparable to atopic asthma. 450 Am J Respir Crit Care Med. 2008 Sep 1;178(5):476-82.

451 28. Saglani S, Payne DN, Zhu J, Wang Z, Nicholson AG, Bush A, et al. Early detection of 452 airway wall remodeling and eosinophilic inflammation in preschool wheezers. Am J Respir Crit Care Med. 2007 Nov 1;176(9):858-64. 
29. Maclennan C, Hutchinson P, Holdsworth S, Bardin PG, Freezer NJ. Airway inflammation in asymptomatic children with episodic wheeze. Pediatr Pulmonol. 2006 Jun;41(6):577-83.

456 30. Schefold JC, Hasper D, von Haehling S, Meisel C, Reinke P, Schlosser H-G. Interleukin-6 serum level assessment using a new qualitative point-of-care test in sepsis: A comparison with ELISA measurements. Clin Biochem. 2008 Jul;41(10-11):893-8.

\section{TABELS}

461 Table 1. Raw immune mediator levels measured during episodes of asthma-like symptoms

$462(\mathrm{~N}=490)$ and in asymptomatic periods $(\mathrm{N}=434)$.

\begin{tabular}{|c|c|c|}
\hline Immune mediator & $\begin{array}{l}\text { Asymptomatic ( } \mathrm{n}=434) \\
\text { median [IQR] }(\mathrm{pg} / \mathrm{mL})\end{array}$ & $\begin{array}{c}\text { Asthma-like symptoms }(\mathrm{n}=490) \\
\text { median }[\mathrm{IQR}](\mathrm{pg} / \mathrm{mL})\end{array}$ \\
\hline IL-12p70 & $1.1[0.3,2.0]$ & $1.6[0.8,2.3]$ \\
\hline CXCL10 & $3369.8[1184.5,5740.2]$ & $4999.9[2401.2,7364.3]$ \\
\hline IFN- $\gamma$ & $3.2[1.3,7.7]$ & $7.7[3.7,16.3]$ \\
\hline TNF-a & $19.3[6.0,82.1]$ & $74.6[24.4,203.7]$ \\
\hline CCL4 & $346.8[96.9,1163.2]$ & $870.7[312.3,2047.1]$ \\
\hline CCL2 & $103.6[44.1,206.3]$ & $153.9[84.0,278.5]$ \\
\hline CCL11 & $151.4[67.7,272.9]$ & $208.5[116.6,333.7]$ \\
\hline CCL13 & $13.8[7.1,20.7]$ & $13.2[8.2,18.2]$ \\
\hline IL-4 & $0.7[0.2,1.5]$ & $1.1[0.2,2.5]$ \\
\hline IL-5 & $1.7[0.8,3.3]$ & $2.1[1.2,3.6]$ \\
\hline IL-13 & $15.3[8.5,21.8]$ & $15.3[10.4,21.2]$ \\
\hline CCL26 & $7.7[2.4,14.7]$ & $13.1[4.5,20.8]$ \\
\hline CCL17 & $12.8[7.1,19.5]$ & $14.7[9.8,20.4]$ \\
\hline CCL22 & $482.6[315.2,689.3]$ & $477.2[304.5,668.9]$ \\
\hline IL-1ß & $208.6[50.8,820.3]$ & $485.7[154.0,1179.9]$ \\
\hline CXCL8 & $11982.3[3563.2,16969.7]$ & $14846.8[8625.5,18807.9]$ \\
\hline IL-10 & $10.1[3.7,20.8]$ & $19.2[10.4,39.7]$ \\
\hline IL-2 & $1.0[0.3,2.0]$ & $1.1[0.5,2.2]$ \\
\hline
\end{tabular}


464 Table 2. Upper airwayimmune mediator levels during episodes of asthma-like symptoms $(\mathrm{N}=490)$ compared to asymptomatic periods (N=434). CI95: $46595 \%$ confidence interval. *False discovery rate adjusted $p$-value. 


\begin{tabular}{|c|c|c|c|c|c|}
\hline Immune mediator & $\begin{array}{l}\text { Immune } \\
\text { response class }\end{array}$ & $\begin{array}{l}\text { Ratio of immune mediator levels } \\
\text { (asthma-like symptoms / } \\
\text { asymptomatic) }\end{array}$ & $\mathrm{Cl} 195$ & p-value & $\begin{array}{l}\text { Corrected } \\
\text { p-value* }\end{array}$ \\
\hline IL-12 & Type 1 & 1.17 & {$[0.76: 1.79]$} & 0.48 & 0.79 \\
\hline CXCL10 & Type 1 & 1.06 & {$[0.81: 1.39$ ] } & 0.68 & 0.86 \\
\hline IFN- $\nu$ & Type 1 & 1.73 & {$[1.33: 2.26]$} & $<0.01$ & 0.06 \\
\hline TNF- $\alpha$ & Type 1 & 2.05 & {$[1.55: 2.72]$} & $<0.01$ & 0.02 \\
\hline CCL4 & Type 1 & 1.23 & {$[0.93: 1.62$ ] } & 0.15 & 0.37 \\
\hline CCL2 & Type 1 & 0.99 & {$[0.73: 1.34]$} & 0.96 & 0.96 \\
\hline CCL11 & Type 2 & 0.95 & {$[0.66: 1.36]$} & 0.77 & 0.86 \\
\hline CCL13 & Type 2 & 0.74 & {$[0.51: 1.06$ ] } & 0.11 & 0.34 \\
\hline IL-4 & Type 2 & 0.84 & {$[0.62: 1.15$ ] } & 0.29 & 0.53 \\
\hline IL-5 & Type 2 & 0.83 & {$[0.47: 1.48$ ] } & 0.54 & 0.81 \\
\hline IL-13 & Type 2 & 0.89 & {$[0.56: 1.40]$} & 0.60 & 0.84 \\
\hline CCL26 & Type 2 & 0.76 & {$[0.54: 1.07]$} & 0.16 & 0.37 \\
\hline CCL17 & Type 2 & 1.07 & {$[0.75: 1.53]$} & 0.72 & 0.86 \\
\hline CCL22 & Type 2/Treg & 0.65 & {$[0.43: 0.99]$} & 0.05 & 0.18 \\
\hline IL-1ß & Type 17 & 1.45 & {$[1.13: 1.87]$} & 0.01 & 0.06 \\
\hline CXCL8 & Type 17 & 1.03 & {$[0.71: 1.49$ ] } & 0.87 & 0.92 \\
\hline IL-10 & Regulatory type & 1.97 & {$[1.39: 2.79]$} & 0.02 & 0.11 \\
\hline
\end{tabular}

This article is protected by copyright. All rights reserved 
470 Table 3. Treatment effect of azithromycin for episodes of asthma-like symptoms depending on upper airway immune mediator levels.

471 CI95: 95\% confidence interval. SD: Standard deviation. *p-value for interaction.

\begin{tabular}{|c|c|c|c|c|}
\hline $\begin{array}{l}\text { Immune } \\
\text { mediator }\end{array}$ & $\begin{array}{c}\text { Treatment effect } \\
\text { (factor / increase SD of concentration) }\end{array}$ & Cl95 & p-value* & $\begin{array}{l}\text { Concentration of no treatment } \\
\text { effect (SD) }\end{array}$ \\
\hline TNF- $\alpha$ & 0.50 & {$[0.28: 0.90]$} & 0.03 & $>0.95$ \\
\hline CCL22 & 2.36 & {$[1.15: 4.84]$} & 0.02 & $<-0.71$ \\
\hline IL-10 & 0.50 & {$[0.27: 0.94$ ] } & 0.04 & $>0.90$ \\
\hline
\end{tabular}




\section{FIGURE LEGENDS}

475 Figure 1. Study base selection of upper airway epithelial lining fluid samples obtained from young

476 children during episodes of asthma-like symptoms and in asymptomatic periods. Samples were

477 analyzed for levels of various immune mediators (i.e. cytokines and chemokines). *Stokholm et al. 478
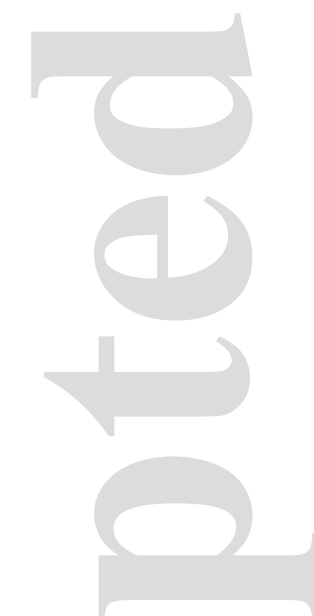

This article is protected by copyright. All rights reserved 
479 Figure 2. Immune mediator levels during episodes of asthma-like symptoms ( $\mathrm{N}=490$ samples) compared to in asymptomatic periods ( $\mathrm{N}=434$ 480 samples).

Figure 3. Top panel: Duration of episodes of asthma-like symptoms with various immune mediator levels in episodes treated with azithromycin $(\mathrm{N}=32)$ and placebo $(\mathrm{N}=38)$. Green lines: placebo group; orange lines: azithromycin group. Bottom panel: Treatment effect of azithromycin for episodes of asthma-like symptoms with various immune mediator levels. Treatment effect is the calculated difference in symptom duration between the placebo and the azithromycin group for any immune mediator level. X-axis indicators signifies observations.

This article is protected by copyright. All rights reserved 

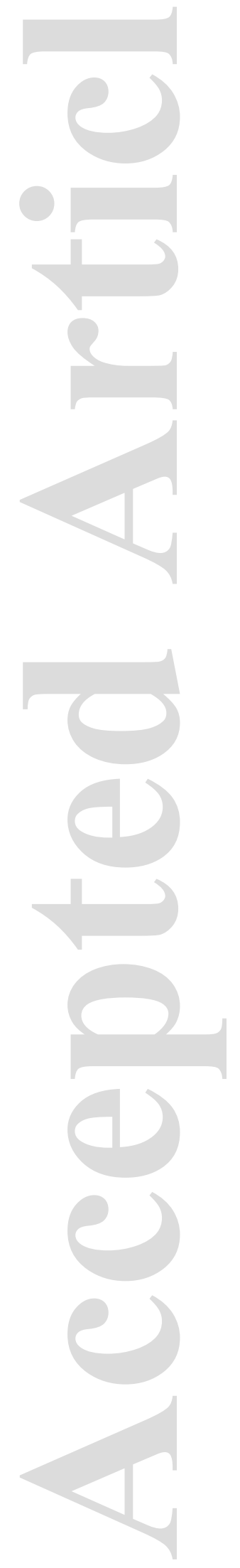

This article is protected by copyright. All rights reserved 


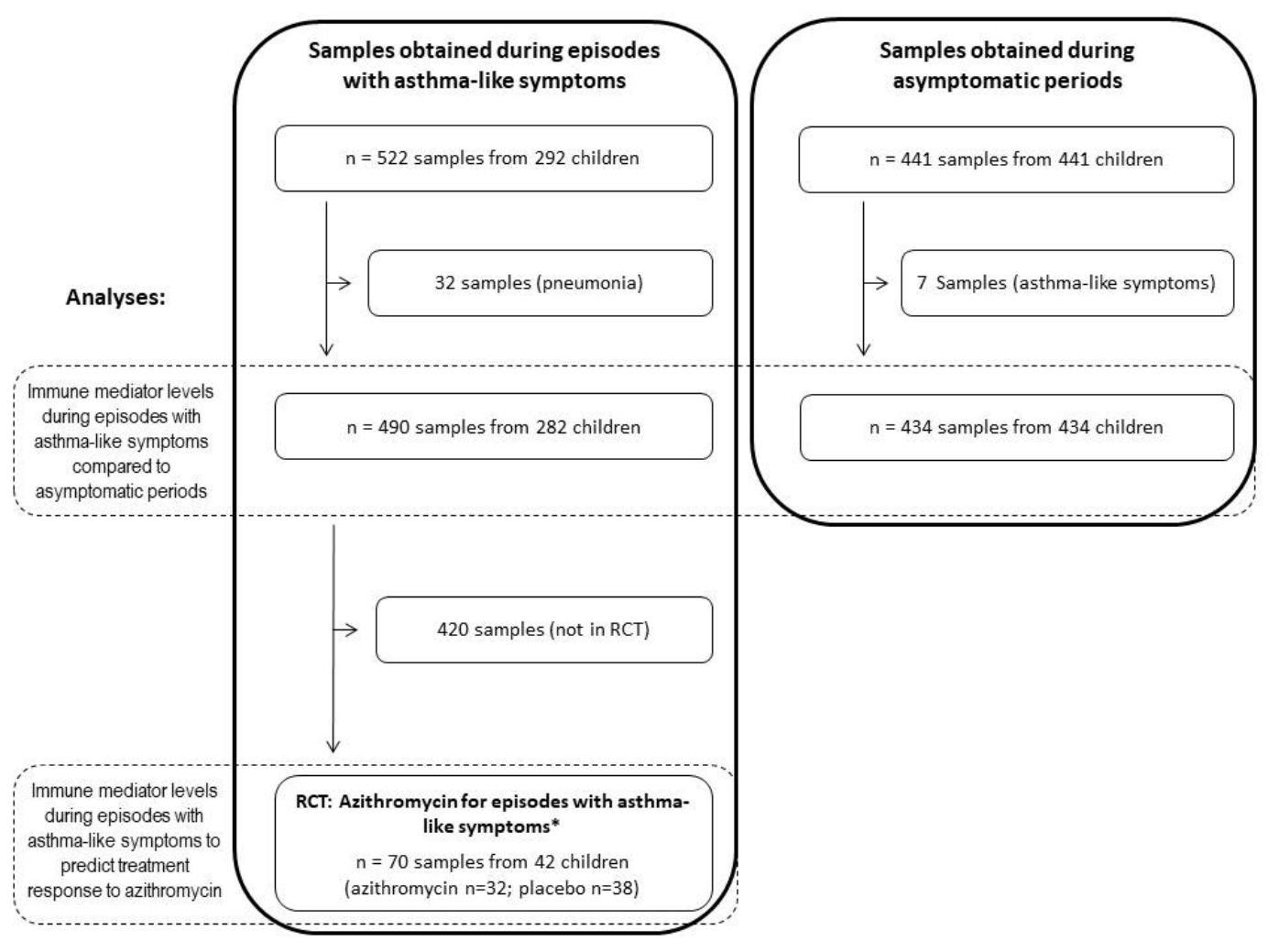

all_14651_f1.jpg 


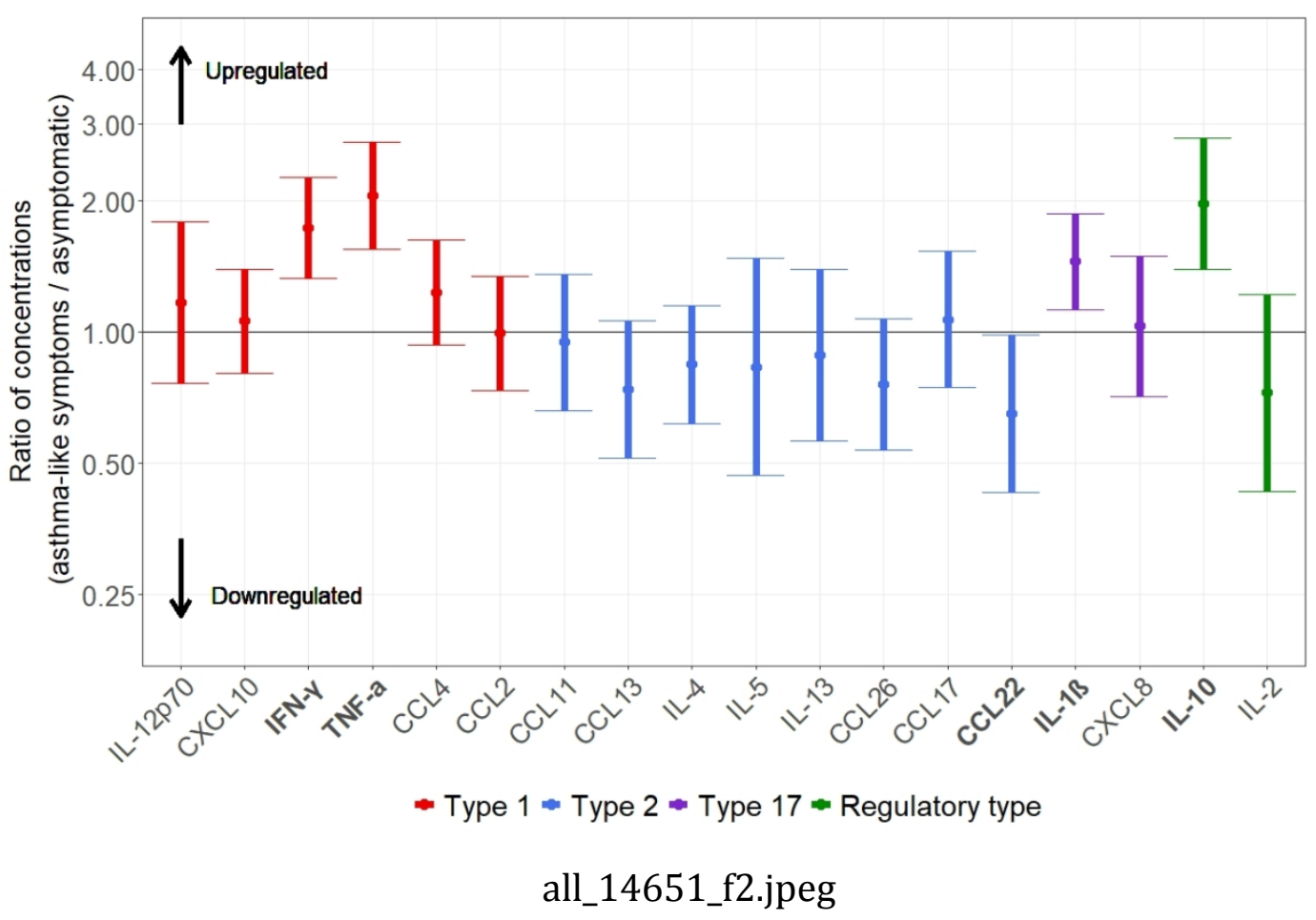

This article is protected by copyright. All rights reserved 

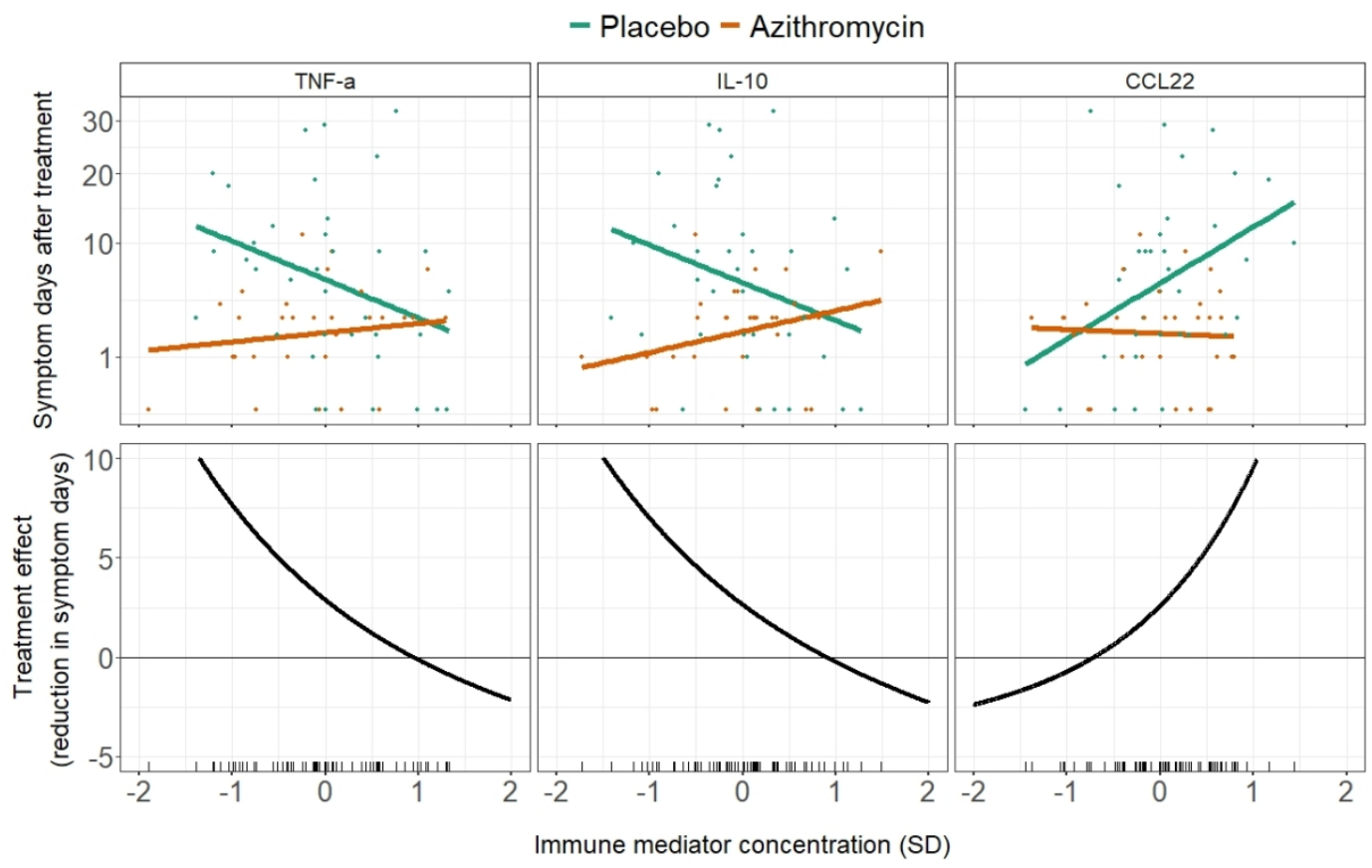

all_14651_f3.jpeg 